\title{
Research on Strategy of Optimized Allocation of Higher Education Resource
}

\author{
Linlin \\ Institute for Higher Education, \\ Jilin Agricultural University, \\ Changchun, China \\ linlinjlau@126.com
}

\begin{abstract}
Whether the higher education resource allocation is reasonable or not is directly related to the utilization efficiency of educational resource and the allocation of internal education resource of universities concerns with their own survival and development. This paper conducts preliminary exploration on the principles and approaches that the optimized allocation of resources should adhere on the basis of revealing the present situation and problems of the allocation of internal resource of universities.
\end{abstract}

Keywords-higher education, resource allocation,
optimization, strategy

\section{INTRODUCTION}

The resources of high education is the base of its proceeding to improve. It aims to stream line and promote the development of high education, which is the necessary premise of its function. The resources of high education is a constant changing concept and its is still a global concern. The key to solve the problem of scarce is to optimize the resources of high education. So, the concern on the resources optimization of high education becomes the core of theory and practice, as it breaks up the traditional basic theory. Because it is difficult to measure the quality of high education and impossible to predict the up and down cost of the organization, meanwhile, the human capital isn't fixed and the information communication isn't adequate, the resources optimization of high education is hampered, both in theoretical research and practical operation. Now it's very urgent to set up a system to study there sources optimization of high education to realize its constant, healthy development.

\section{THE SIGNIFICANCE OF OptIMIZED ALLOCATION OF HigHER EDUCATION RESOURCE}

A The optimized allocation of higher education resource can enhance the ability of universities to avoid risks

How to allocate universities' resources depends on educational resource stock before enrollment expansion, the requirements of long-term school size, school orientation and educational goals of universities, as well as the social requirements to the development of higher education and the policy orientation of government for the development of higher education. Accordingly, during the process of education resource allocation, universities must study how to take full advantage of the existing school resources and grasp the social demand for higher education development, and the significance of the social contribution of universities to the total social utility ${ }^{[1]}$. Figure out what resources need to consume and how much each resource consumption is to cultivate graduates and provide social services and scientific research under the prevailing socio-economic and policy conditions at the same time. Then analyze the scarcity of their own resources. Integrate the result analysis and compare various allocation programs of educational resources and ultimately determine the best program to achieve the educational goals under the specific conditions of the present and the future. Universities must conduct the optimal allocation of educational resources in the new campus in order to effectively improve the ability to resist various risks during the development process.

B The optimized allocation of higher education resource is conducive for universities to achieve their function

The achievement of universities' three functions is the result of the combined effects of higher education resources. The effect of optimized allocation of higher education resource determines the effectiveness and benefits of various higher education resource utilization and personnel training. The specific roles of higher education resources on personnel training are reflected in the growth of knowledge and the improvement of personnel quality and capacity. By utilizing higher education resources, universities foster personnel's social quality ${ }^{[2]}$. Under certain educational resources, the better the resources are used, the higher the social quality of students is and the better they can take advantage of their potential. Higher education resources imparts students more systematic and cutting-edge knowledge, which is converted to their skills through experiments, training, practical training and other practical aspects of higher education. Universities provide social services through the socialization of higher education resource and take part in the realization of social service functions through scientific research and research results, which are all dependent on the function of higher education resources. To create a good environment for students' growth through the optimized allocation of higher education resource is the problem that must be solved for universities. This requires that universities must establish a resource allocation concept based on student-centered and focus on establishing long-term development goals and optimize the allocation of educational resources. 
C The optimized allocation of higher education resource can promote universities' disciplinary construction

Universities are discipline-based academic organization and all its features and attributes are discipline related. Universities should actively promote the disciplinary construction, especially the construction of key disciplines, to enhance the overall strength and competitiveness of the school through optimizing internal and external environment and integrating resources. According to the demands of disciplinary construction, take the actual situation of each discipline and campus circumstances into overall consideration and restructure discipline into three types based on its nature: foundation, application and technology. Mutual support is formed among discipline groups depending on the desired environment for disciplinary development. It is convenient for the exchange and communication of information and sharing of resources and makes all disciplines of the school combine into an organic entirety, which is conducive to the coordinated development of various disciplines.

\section{$D$ The optimized allocation of higher education resource can improve the efficiency of universities}

The Management of colleges and universities, from a functional view, is that managers adopt certain means and methods to decide, plan, organize and regulate education activity, in order to effectively implement school educational goals. From a management target point of view, it is the management of educational resources. The efficiency of universities is their capabilities to apply educational resources and the actual results. Therefore, the effect of educational resource optimization is an important manifestation of efficiency of universities. Only with the prerequisite of educational resources management and the optimized allocation of education resource, can the potential of all types of educational resources be given full play ${ }^{[3]}$. The educational goals of universities can be achieved and more and higher quality talents who can meet the reasonable demands of the public can be cultivated. It is thus clear that the optimized allocation of education resource plays an important role in improving the efficiency of universities.

\section{WAYS FOR OPTIMIZED ALLOCATION OF UNIVERSITIES' INTERNAL RESOURCES}

In order to achieve the optimal allocation of internal resources, universities should realize the minimized higher education resource input under the premise of creating and maintaining their own characteristics and advantages and ensuring qualified personnel to the society. Universities must innovate their internal system, improve teaching efficiency, avoid all kinds of waste and losses as much as possible, and optimize the allocation of educational resources consumption.

A Adjust the size of schools, strengthen faculty and achieve economies of scale.
Universities should control enrollment from the practical point of view. To achieve economies of scale, from the human resources point of view, is to achieve the rationalization of student-teacher ratio. Only with sufficient quantity and quality of investment in human resources, can high quality educational outcomes be ensured. Two ways can be adopted. One is external introduction. Introduce first-class faculty, especially a group of academic backbone of their own disciplinary field and academic leaders with outstanding achievements to establish disciplines of first-level. The other is internal mining ${ }^{[4]}$. Strengthen the training and supervision of internal teachers and explore their potentials. Teachers should also complete certain research work in addition to accomplish teaching work meeting both quality and quantity standards. Urge teachers to learn and strive to improve their teaching and research ability. With reasonable student-teacher ratio improve their own teaching ability and teaching quality, which means improving resource utilization in order to achieve economies of scale.

$B$ Deepen the internal management system in university and enhance efficient use of resources.

Apply the multi-directional triage approach into excess staff according to the scope of the sector. Teachers who are in line with the conditions are to enrich the front line of teaching and research and who are not are diverted to school-run industries or other service jobs. Teachers on management positions can do different positions at the same time. In addition, the development of higher education requires appropriate logistical support system. The resources allocation between university logistics and society can not only improve the efficiency of resource allocation of university logistics but also greatly promote the development of higher education.

$C$ Implement open management public facilities and achieve sharing of resources.

Resource which includes both sharing among the various professions and sharing among neighboring universities and research institutions. High-valued research, teaching equipment, computers and internships, laboratory space, library materials, sports facilities should be open to each other. The owners and users of resources should facilitate mutual convenience and implement paid services. Universities can gain economies of scale only by achieving full utilization of resources. Internal teaching staff should also be optimized to achieve sharing of resources among various professionals. The reduced investment on building qualified teachers queue, teaching equipment purchase, laboratory construction due to the sharing of resources among the various professions with stronger professional compatibility is conducive to the mutually reinforcing among various professionals. Reduce student training costs and improve the efficiency of higher resource allocation at the micro level ${ }^{[5]}$.

$D$ Integrated disciplines, form characteristics and reorganize resource. 
The integration of Disciplines and professions is to optimize the discipline and professional structure and promote disciplinary and professional development. From the perspective of optimizing the structure, the allocation of disciplinary strength and resources should be beneficial not only to maintaining and developing the school's advantage in several disciplines and the formation of leading discipline and special discipline, but also to the cross-penetration between disciplines and the creation of academic environment favorable to disciplinary symbiosis. Select preferentially based on the size of discipline and professional yield. Avoid two extreme tendencies of too centralized and decentralized educational resource allocation and strive to achieve the optimal allocation of educational resources. During the integration process, schools should look for their own advantage and form their own school characteristics focusing on "special" "excellent" rather than "big" "full."

\section{E Allocate resources flexibly by "retaining one and releasing many".}

Treat different disciplines, specialties, and schools differently. The disciplinary and profession of universities can be divided into two categories: application-oriented (such as computers, electronic communications) and basic type (such as math). The resource issues of the two types should be addressed through two different channels. That is to say, market mechanisms should be applied to allocate resources for application-oriented disciplinary and profession while the basic type, including some new subjects which have not been popular and some unpopular majors, should depend on the institutionalized donations of schools, governments and various foundations making them able to get access to various types of resources needed for its continued development. In a word, it is "retaining one and releasing many" by adopting the mixed resource allocation combining market and program.

\section{CONCLUSION}

On the optimized allocation of higher education resource, the core issues of theoretical and practical higher education, theoretically we need to analyze it from the changing social reality. The policies and regulations and legal standards of higher education resource allocation should reflect the inevitable trend of the combination of resource elements in the development process of universities. Practically, we need to reasonably analyze criteria for judging and evaluation methods of the optimized allocation of higher education resource and conduct targeted selection.

\section{REFERENCES}

[1] Yu Hongliang. Mode and Route Choice of the Optimized Allocation of Higher Education Resource [J]. Education and Profession, 2009 (14) : 21-23.

[2] Feng Yan, Gao Yanying. The Literature Review on Research of Higher Education [J].Modern Education Management, 2012(11):18-22.

[3] Qian Zhifa,Yang Liang. Research on Construction of the Allocation of Regional Higher Education Resource [J].Journal of Jiangsu University of Science and Technology, 2010(4):87-90.

[4] Gao Jian. Research on Higher Education Resource Allocation [D]. Nanjing: Nanjing University of Aeronautics and Astronautics, 2010:35-47.

[5] Tan Guangxin. The Optimized Allocation of Higher Education Resource Based on Pareto Genetic Algorithm [J]. Science and Technology Management Research, 2010(11):70-74. 